\title{
Ureaplasma urealyticum gen. nov., sp. nov.: Proposed Nomenclature for the Human T (T-Strain) Mycoplasmas
}

\author{
M. C. SHEPARD, C. D. LUNCEFORD, D. K. FORD, R. H. PURCELL, \\ D. TAYLOR-ROBINSON, S. RAZIN, and F. T. BLACK
}

\begin{abstract}
Division of Microbiology, Naval Medical Field Research Laboratory, Camp Lejeune, North Carolina 28542; Department of Medicine, Faculty of Medicine, University of British Columbia, Vancouver General Hospital, Vancouver, Canada; Laboratory of Infectious Diseases, National Institute of Allergy and Infectious Diseases, Bethesda, Maryland 20014; Clinical Research Centre, Watford Road, Harrow, Middlesex HAI 3 UJ, England; Department of Clinical Microbiology, The Hebrew University-Hadassah Medical School, Jerusalem, Israel; Institute of Medical Microbiology, University of Aarhus, Aarhus, Denmark
\end{abstract}

The biological properties and special characteristics of the human $T$ mycoplasmas have been reviewed and summarized. The $T$ mycoplasmas are distinguished from all other known mycoplasmas by their production of urease, and, therefore, by their ability to hydrolyze urea. This singular property significantly sets the $\mathrm{T}$ mycoplasmas apart from all other members of the order Mycoplasmatales. In consideration of this distinguishing property, it is reasonable to propose establishing a new, separate genus in the family Mycoplasmataceae in which to classify the $\mathrm{T}$ mycoplasmas isolated from man and lower animals. The name Ureaplasma is proposed for this new genus, which at present contains a single human species of at least eight different serotypes. The name Ureaplasma urealyticum is proposed for this new species. The type strain of $U$. urealyticum is human strain $960-(\mathrm{CX} 8)$, serotype VIII (Black); it has been deposited in the American Type Culture Collection as ATCC 27618.

$T$ mycoplasmas were first recognized and identified in 1954 in primary agar cultures of urethral exudates from male nongonococcal urethritis patients. They were called "tiny-form PPLO" (pleuropneumonia-like organisms) and "T-form colonies of PPLO" after the minute size, distinctive characteristics, and morphology of their agar colonies. The first published reference to these unusual mycoplasmas was a brief description accompanying two photomicrographs of " $T$ " colonies in a primary agar culture of urethral exudate (53). Subsequent studies confirmed that $\mathrm{T}$ mycoplasmas were new, previously undescribed members of the human mycoplasma group. Their distinctive morphology and cultural characteristics were described and illustrated in detail in 1956 (54). The original minute colony size $(10 \pm 5 \mu \mathrm{m})$ was the result of nutritionally inadequate culture media of distinctly unfavorable alkaline reaction ( $\mathrm{pH} 7.8$ to 8.0 ) resulting in near threshold performance in supporting growth of $T$ mycoplasmas. Some of the early failures of other investigators to isolate $\mathrm{T}$ mycoplasmas from clinical exudates may also be explained by the incorporation by these investigators of thallium acetate in the medium in accordance with standard classical mycoplasma methodology. This antibacterial agent is almost completely inhibitory to many strains of T mycoplasmas in primary agar cultures in alkaline media of $\mathrm{pH} 7.8$ to 8.0 . Thallium acetate was never employed in Shepard's laboratory, where only penicillin was incorporated as an antibacterial agent $(1,000 \mathrm{U} / \mathrm{ml})$.

Prior to 1966, identification of $\mathrm{T}$ mycoplasmas in primary cultures was limited exclusively to characteristic minute size, morphology, and staining reaction of agar colonies. The subsequent development of improved agar culture media made identification based upon the above-mentioned criteria less reliable, since $T$ colonies were no longer really "tiny." Identification was especially difficult under conditions of crowding in mixed mycoplasma cultures since classical mycoplasma colonies often completely lost the ability to produce the surface growth zones (by which they are so readily recognized) and resembled $\mathrm{T}$ colonies. The utilization of certain distinctive bio- 
chemical properties of $\mathrm{T}$ mycoplasmas, in addition to morphology, size, and staining reaction of agar colonies, subsequently provided reliable means of identification and characterization of the T-mycoplasma group (56-58). The most unique and distinguishing biochemical property of the T-mycoplasma group is the production of urease with the resultant ability to hydrolyze urea with the production and accumulation of ammonia (24, $48,56,64)$. This property is specific for $T$ mycoplasmas, since no other presently known mycoplasmas produce urease. Three different laboratory procedures, based upon demonstration of T-mycoplasma urease (61), have been developed for the detection and identification of $\mathrm{T}$ mycoplasmas in clinical material and in cultures: sensitive urease color test media (61, $65,72,75)$; a direct test for urease in agar colonies (62); and a differential agar medium, A-6, for the detection and identification of $T$ mycoplasmas in primary cultures (M. C. Shepard and C. D. Lunceford, Bacteriol. Proc., p. 83, 1970). The metabolism-inhibition test, a highly useful serological procedure for the measurement of antibody to $T$ mycoplasmas, has also been developed and is based upon the inhibition of urea metabolism by specific antiserum (48).

The term "T-strain" of mycoplasma ( $T$ mycoplasmas) was originally intended to be a temporary designation for this unique group of mycoplasmas. With increasing interest in $T$ mycoplasmas and their possible role in certain diseases of humans and lower animals, it has now become necessary to abandon this temporary tag. Sufficient fundamental knowledge of the biological properties of the $\mathrm{T}$ strains has now accumulated to warrant proposing a name to recognize them formally as members of a new human species in the family Mycoplasmataceae. The purposes of this communication are: (i) to summarize the biological properties of this distinctive mycoplasma group, (ii) to propose a new genus in which to classify the $\mathrm{T}$ mycoplasmas, (iii) to propose a species name for these organisms, and (iv) to designate the type strain of the species.

\section{DESCRIPTION}

The biological properties of the type strain appear to be essentially identical to the biological properties of all other strains of the proposed species (except for antigenic and minor quantitative differences, and differences in fastidiousness). Therefore, the type strain is described in combination with the proposed species.

Morphology. Morphologically, T-mycoplasma organisms appear to be basically simple; in general they consist of round or coccobacillary elements approximately $0.3 \mu \mathrm{m}$ in diameter. In Giemsa-stained smears of clinical exudates and fluid cultures, the organisms frequently appear with one end pointed. Recent examinations by electron microscopy suggest that the pointed end is really a small bud (M. C. Shepard and C. D. Lunceford, unpublished data). As with other Mycoplasma species, short bacillary elements or "filaments," annular forms, signet-ring-forms, and bipolar elements can often be observed, depending upon the strain, age of the organisms, and method of examination. The basic mode of multiplication of $\mathrm{T}$ mycoplasmas in a liquid medium is believed to consist of a simple budding process, in different directions, producing either single organisms, pairs, small aggregates, or multidirectional, ramifying (filamentous) elements which continue to multiply, producing growth aggregations or colonies in fluid and in agar cultures (58). A similar mode of multiplication has been observed in association with infected epithelial cells from the urethral mucosa of urethritis patients. The organisms are gram negative but stain weakly by this method $(55,58)$. The ultrastructure of T-mycoplasma organisms grown in fluid medium, as observed by electron microscopy of embedded, ultrathin sections, consists of mostly rounded cells ranging in size from 0.12 to $0.46 \mu \mathrm{m}$ in diameter; however, filamentous elements greater than $2.0 \mu \mathrm{m}$ long by 0.15 to $0.20 \mu \mathrm{m}$ in diameter also occur (52). T-mycoplasma organisms are bounded by a single, triple-layered membrane $(7,52)$. The outer surface of this membrane has been shown to be covered by an electron-dense layer consisting of short, radiating, hairlike structures (7) resembling closely spaced "brush bristles." In addition, ribosomes, frequently arranged in regular, geometric patterns, were clearly demonstrated, and intracellular vacuole-like structures were also observed in the T-mycoplasma organisms (7).

Cultural characteristics. On appropriate horse serum agar media, colonies of $\mathrm{T}$ mycoplasmas are generally small (20 to $30 \mu \mathrm{m})$ and normally without zones of surface growth. In the absence of crowding, and depending also on strain differences (which may be significant among the $\mathrm{T}$ mycoplasmas), agar colonies may attain 30 to $40 \mu \mathrm{m}$ in diameter. They are generally circular in shape and are characterized by an irregular border. Larger colonies (uncrowded) 
are often multilobate and exhibit a characteristic "cauliflower head" colony. Colony growth is generally visible after $24 \mathrm{~h}$, and maximum size is reached after $48 \mathrm{~h}$ of incubation at $36 \mathrm{C}$. Under special conditions, such as increased carbon dioxide tension ( $20 \%$ in air or nitrogen), increased agar hardness, and cation content (Shepard and Lunceford, unpublished data), or incorporation of HEPES buffer (44), zones of surface growth may develop in agar cultures. Under such conditions, T-mycoplasma colonies mimic those of classical, large-colony $\mathrm{Myco}$ plasma species with which they could be confused. In primary agar cultures of clinical exudates, multiple T-mycoplasma colonies frequently develop into the agar medium beneath deposits of infected epithelial cells (especially from nongonococcal urethritis patients who are treatment failures). Colonies $(48 \mathrm{~h})$ stain blue to greenish-blue in wetstained, agar-block preparations stained with Dienes stain $(18,43)$, but colonies $72 \mathrm{~h}$ or older may stain poorly or remain unstained. New methods for identification of T-mycoplasma colonies in agar cultures, based upon demonstration of urease, have been developed which permit reliable, specific identification (61). One method is a spot test employing a combination of enzyme substrate and test reagent which is applied directly to 48-h-old agar colonies (62). The other method is a differential agar medium (M. C. Shepard and C. D. Lunceford, Bacteriol. Proc., p. 83, 1970) which incorporates the biochemical principle of the direct spot test. An improved version of the differential agar medium has been developed (Shepard and Lunceford, manuscript in preparation). By either method, agar colonies of $\mathrm{T}$ mycoplasmas are specifically identified by development of a dark, golden-brown or bronze-colored manganese reaction product which precipitates on the surface of the T-mycoplasma colonies. These highly distinctive manganese accretion colonies are dark bronze-colored by direct transmitted light through the microscope but white when viewed by oblique-transmitted or oblique-reflected light (such as from an illuminator or desk lamp).

Broth cultures of T-mycoplasma organisms are generally clear and without evidence of turbidity due to growth. Growth occurs rapidly in broth cultures, and maximum concentrations are reached after only 16 to $20 \mathrm{~h}$ of incubation at $36 \mathrm{C}$ (20; Shepard and Lunceford, unpublished data). Broth cultures in a medium of $\mathrm{pH}$ 6.0 (supplemented with 1 to $10 \%$ yeast extract and 10 to $20 \%$ unheated normal horse serum) generally yield titers of $10^{5}$ to $10^{7}$ colonyforming-units (CFU) per milliliter. The number of T-mycoplasma organisms progressively declines in horse serum broth cultures after 16 to $20 \mathrm{~h}$ of incubation, and such cultures are likely to be nonviable after 48 to $72 \mathrm{~h}$ at $36 \mathrm{C}$. In $\mathrm{pH}$ 6.0 broth supplemented with 0.05 to $0.1 \%$ urea and phenol red indicator, titrations of $\mathrm{T}$ mycoplasmas conducted in such broth are expressed as color-changing-units (CCU) per milliliter $(48,65,72)$. Unbuffered urea broth cultures undergo very rapid loss of viability as soon as the reaction approaches $\mathrm{pH} 8.0$, which is lethal for T-mycoplasma organisms (24). Ammonia concentrations which exceed 200 $\mu \mathrm{g} / \mathrm{ml}$ in broth cultures coincide with decline in viability. However, prolongation of stationaryphase growth of T mycoplasmas for $72 \mathrm{~h}$ at titers of $10^{4}$ to $10^{7} \mathrm{CCU} / \mathrm{ml}$ in urea broth has been achieved by a vacuum-flow system which maintains the ammonia concentration below $200 \mu \mathrm{g} / \mathrm{ml}$ (32). A continuous culture system in a closed apparatus, employing the principle of a "chemostat," has also been successfully used for the cultivation of $\mathrm{T}$ mycoplasma in fluid culture. Viable counts of $10^{5}$ to $10^{6} \mathrm{CFU} / \mathrm{ml}$ were achieved in continuous cultivation over a period of 9 days by means of this system (12). It has been suggested that another possible explanation for the rapid decline of viability of T-mycoplasma broth cultures is the accumulation of a catalase-resistant, heat-stable ( $56 \mathrm{C}$ for $5 \mathrm{~min}$ ), dialyzable toxic product (27). Special modifications of urea broth have been developed for (i) the detection and identification of T mycoplasmas in clinical materials (65), (ii). the direct titration of these mycoplasmas in clinical materials and in cultures $(65,72)$, and (iii) the measurement of antibody to $\mathrm{T}$ mycoplasmas by means of a metabolism-inhibition color test (48).

Physiological characteristics: optimal reaction for growth. In contrast to the optimal reaction for growth of the classical, largecolony human mycoplasmas, $\mathrm{T}$ mycoplasmas require an acid reaction of $\mathrm{pH} 6.0 \pm 0.5$ in agar and in broth cultures for best growth (63).

Gaseous requirement. $T$ mycoplasmas are microaerophilic. A gaseous mixture containing from 5 to $15 \%$ carbon dioxide in nitrogen or air is required for best growth in agar cultures. It is not essential to use nitrogen as an inert gas, since mixtures of 5 to $15 \%$ carbon dioxide in air appear to yield equally satisfactory growth (Shepard and Lunceford, unpublished findings). Aerobic growth of $\mathrm{T}$ mycoplasmas in agar cultures (without increased carbon dioxide tension) was first achieved in agar cultures of $\mathrm{pH} 5.5$ to 6.0 (63), but growth was slow and variable, and colonies were suboptimal in size and density. Excellent anaerobic growth of $\mathrm{T}$ 
mycoplasmas is achieved in agar cultures of $\mathrm{pH}$ 6.0. However, it is emphasized that little or no growth of $\mathrm{T}$ mycoplasmas occurs under anaerobic cultivation in alkaline agar cultures of $\mathrm{pH}$ 7.8 to 8.0 (Shepard and Lunceford, unpublished findings). The failure of $\mathrm{T}$ mycoplasmas to grow anaerobically in alkaline agar media (based on studies and culture media employed prior to 1964) explains the contradiction previously published (58).

Action on carbohydrates. The usual carbohydrates are not fermented by $T$ mycoplasmas, as determined by conventional indicator colorchange methods in carbohydrate-containing growth media. T mycoplasmas lack hexokinase activity (6).

Serum requirement. The serum requirement is best served by supplementation of the medium with 10 to $20 \%$ unheated, normal horse serum. However, essentially no growth of $\mathrm{T}$ mycoplasmas occurs in the absence of serum. Two metabolites which are utilized by $\mathrm{T}$ mycoplasmas are furnished by the serum enrichment, namely urea and cholesterol, and these will be discussed separately. There appear to be other important, presently unknown factors in fresh horse serum which may be required or are stimulatory for growth of $\mathrm{T}$ mycoplasmas. These factors are best preserved by storage of normal horse serum in the frozen state (Shepard and Lunceford, unpublished data). For isolation of $\mathrm{T}$ mycoplasmas in primary cultures from clinical exudates, $20 \%$ horse serum enrichment is recommended.

Amino acid requirement. The usual amino acids do not appear to be utilized, and very little is known concerning the precise amino acid requirements for $T$ mycoplasmas. However, L-histidine appears to act per se rather than through a metabolic product in stimulating T-mycoplasma growth, possibly through competition with urea in reducing the rate of ureolysis, ammonia production, and rapid rise in $\mathrm{pH}$ (N. Romano, personal communication, 1972). The precise role of L-histidine in the metabolism of $\mathrm{T}$ mycoplasmas is presently obscure. It cannot substitute for urea as a requirement for growth (Shepard and Lunceford, unpublished data). $T$ mycoplasmas are arginine deaminase negative, and arginine is not utilized (79). L-cysteine is beneficial to growth of $\mathrm{T}$ mycoplasmas, and 10-fold-higher numbers of organisms are obtained in horse serum broth cultures containing $0.57 \mathrm{mM}$ concentrations of L-cysteine hydrochloride. This amino acid is also stimulatory to T-mycoplasma growth in a differential agar medium (Shepard and Lunceford, Bacteriol. Proc., p. 83, 1970). The precise mechanism of L-cysteine stimulation of
T-mycoplasma growth is not completely understood. Other thiols, including reduced glutathione, methionine, cystine, thioglycolate, and dithiothreitol, are less effective (Shepard and Lunceford, unpublished data).

Urea requirement. $\mathrm{T}$ mycoplasmas are unique among the Mycoplasmatales in that they produce urease and actively hydrolyze urea with the production of ammonia and carbon dioxide. No other presently-known mycoplasmas contain this enzyme. Urea is believed to be required for best growth and multiplication of $T$ mycoplasmas $(24,48,56,61,64$; Shepard and Lunceford, unpublished data). However, an absolute requirement for urea by $T$ mycoplasmas has not been established, and little is known concerning the urea metabolism of these organisms. It is possible that differences in requirement for urea exist between laboratory stock strains of $T$ mycoplasmas and those isolated in primary cultures from clinical specimens. In a study of T-mycoplasma urease, carbamate ion was found to be an intermediate in a two-step enzyme reaction leading to $\mathrm{HCO}_{3}{ }^{-}$ $+\mathrm{NH}_{3}$ (P. K. Joo, L. Marnell, and P. J. Van Demark, Abstr. Annu. Meet. Amer. Soc. Microbiol., p. 80, 1973). In studies employing ${ }^{14} \mathrm{C}$-labeled urea as substrate for $\mathrm{T}$ mycoplasmas, over $95 \%$ of the radioactivity was recovered as ${ }^{14} \mathrm{CO}_{2}$, but significant radioactivity was not incorporated into cellular material (23). T mycoplasmas have been reported to undergo multiplication in fluid media containing commercially dialyzed calf serum (in place of normal horse serum) plus $0.03 \mathrm{M}$ putrescine. Further, it was found that $0.02 \mathrm{M}$ allantoin could replace urea in dialyzed fluid medium supplemented with dialyzed calf serum, and $0.05 \mathrm{M}$ agmatine replaced putrescine and urea in dialyzed and undialyzed fluid medium in supporting growth of $\mathrm{T}$ mycoplasmas. Other polyamines, including cadaverine, spermidine, and spermine were unable to serve as urea substitutes (47). Employing media containing specially dialyzed horse serum supplementation (residual urea $=0.3 \mathrm{mg} / 100$ $\mathrm{ml}$ ) and inoculated with organisms thrice washed in $\mathrm{pH} 7$ buffered saline, ammonium chloride in concentrations of 1.0 to $20 \mathrm{mM}$ failed to replace urea, and multiplication did not occur in either fluid or agar cultures of $\mathrm{pH}$ 6.0 (Shepard and Lunceford, unpublished data). If $\mathrm{T}$ mycoplasmas incorporate nascent ammonia from urea into organic compounds or otherwise benefit from hydrolysis of urea, the metabolic pathways are unknown. Indeed, the nitrogen metabolism per se of the $\mathrm{T}$ mycoplasmas is essentially unknown.

Sterol requirement. Cholesterol has recently 
been shown to be required by $\mathrm{T}$ mycoplasmas, and the organisms are sensitive to digitonin, amphotericin- $\mathrm{B}$, and progesterone. The sterol requirement could also be met by beta-sitosterol (52). These findings, therefore, place the $\mathrm{T}$ mycoplasmas among the sterol-requiring Mycoplasmataceae. A recent study of the composition and nature of the lipids of $\mathrm{T}$ mycoplasmas demonstrated that cholesterol (as originally reported above), free fatty acids, and phosphatidic acid were the predominant lipids (51). In addition, the remaining neutral lipids were composed of cholesteryl esters, triglycerides, and diglycerides. Other phospholipids and a diamino hydroxy compound were also reported (51).

Fatty acid requirement. Palmitic acid and oleic acid appear to be incorporated by $T$ mycoplasmas, but the purpose and fate of these fatty acids in the metabolism of these organisms are presently unknown (P. F. Smith, personal communication, 1972). Other investigators (52) failed to demonstrate stimulation of growth of $\mathrm{T}$ mycoplasmas by several fatty acids in an albumin-containing medium. However, since the medium could have contained fatty acids in amounts sufficient for limited growth of $T$ mycoplasmas, no definite conclusion can be drawn at present whether these organisms require long-chain fatty acids for growth. The precise role of fatty acids in the metabolism of $T$ mycoplasmas remains to be elucidated.

Yeast extract. It has been standard practice to supplement media for classical mycoplasmas and Mycoplasma pneumoniae with aqueous extracts of brewers yeast. Failure to incorporate yeast extract may result in poor or no growth of classical Mycoplasma species or failure to develop the highly characteristic zones of surface growth. In the case of $T$ mycoplasmas, this practice has continued, and with possibly deficient media the addition of yeast extract may be beneficial. In the laboratory of one of us (MCS), yeast extract was omitted from the agar medium for several years without detectable loss of performance. However, yeast extract was later reinstated in the medium to permit easy recognition of classical Mycoplasma species (in clinical mycoplasma mixtures) by virtue of their characteristic "fried-egg" colony morphology. In certain agar formulae, $10 \%$ supplementation of yeast extract may be slightly inhibitory, and superior performance may be obtained by using lower concentrations (57, 58; Shepard and Lunceford, unpublished data). Yeast extracts are rich in magnesium (31), and growth of $\mathrm{T}$ mycoplasmas in magnesium-deficient broth and agar media is improved by adding magnesium or yeast extract.

Catalase. T mycoplasmas are catalase negative (Shepard and Lunceford, unpublished findings), which is in agreement with the findings for some other mycoplasmas, including, for example, Mycoplasma mycoides subsp. mycoides. $M$. agalactiae, Acholeplasma laidlawii, strains "Campo" (M. arthritidis) $\mathrm{AE}$ and 8490T (78), as well as M. pneumoniae (40).

Tetrazolium and methylene blue. Neither tetrazolium nor methylene blue is reduced by $\mathrm{T}$ mycoplasmas, aerobically or anaerobically (6).

Hemolysin. A soluble hemolysin is produced by $\mathrm{T}$ mycoplasmas which lyses guinea pig erythrocytes $(57,58)$, employing the ery throcyte agar overlay technique $(15,68)$. Slight hemolytic action was observed against human and sheep ery throcytes, but none against horse, calf, ox, swine, rabbit, or chicken ery throcytes under the same experimental conditions. The beta hemolytic plaques were very small $(0.5$ to $2.0 \mathrm{~mm}$ ) but were easily visible by the naked eye. Freshly prepared agar medium was essential for hemolysis $(57,58)$. An alpha-prime type hemolysis has also been reported for human $\mathrm{T}$ mycoplasmas, and the hemolysin is believed to be a peroxide (45). Protection against lysis of erythrocytes close to colonies of $T$ mycoplasmas was observed as frequently as hemolysis, and this may contribute to the difficulty in recognizing weak hemolysis by $\mathrm{T}$-mycoplasma colonies (45). A soluble beta hemolysis was recently demonstrated in a simplified bloodagar plate method (as opposed to the agar overlay method) in all eight T-mycoplasma serotypes (6). The hemolysis completely lysed guinea pig and rabbit erythrocytes under both aerobic and anaerobic conditions, but human erythrocytes were unaffected. Guinea pig erythrocytes were also hemolyzed by $\mathrm{T}$ mycoplasmas in a liquid medium (6).

Tissue-culture cell adsorption. Colonies of six different strains of human $T$ mycoplasmas were found capable of adsorbing $\mathrm{HeLa}$ cells from cell suspensions. Attachment of the cells was tenacious and resisted vigorous washing (44). Specificity of the $\mathrm{HeLa}$ cell adsorption phenomenon was suggested by inhibition of cell attachment by specific antiserum (D. TaylorRobinson, personal communication). In contrast, colonies of canine (semen) and simian (throat) strains of $\mathrm{T}$ mycoplasmas failed to adsorb HeLa cells under identical conditions (44).

Cell proteins. Electrophoretic analysis of cell proteins of 12 different strains of human $T$ mycoplasmas revealed close similarities and 
suggested that the human $\mathrm{T}$ mycoplasmas belong to a single, common group or species (50).

Phosphatase. Phosphatase has been found in over 50 different strains of $\mathrm{T}$ mycoplasmas so far examined (5).

DNA base composition. The melting profiles $\left(T_{m}\right)$ of purified deoxyribonucleic acid (DNA) from seven $\mathrm{T}$ mycoplasmas of different serotype were found to be similar, ranging from 80.65 to $81.00 \mathrm{C}$, with an average value of $80.78 \mathrm{C}$ (1). The base composition of these same seven T-mycoplasma strains, plus T-mycoplasma serotype VIII (8), in mol \% guanine plus cytosine $(\mathrm{G}+\mathrm{C})$ ranged from 27.7 to 28.5 (1). This low $\mathrm{G}+\mathrm{C}$ content is similar to that found for many other mycoplasmas (26 to $32 \%$ ) (42) and suggests genetic homogeneity among the $T$ mycoplasmas.

DNA genome size. The second-order reaction rate constants $\left(K_{2}\right)$ for two T-mycoplasma strains ( $\# 27$ and $\# 58$ of Ford) were found to be 17.39 and 18.72 , respectively (2). The calculated genome size of the DNA from these same two T mycoplasmas was $4.7 \times 10^{8}$ and $4.4 \times$ $10^{8}$ daltons, respectively (2). All eight serotypes of human $\mathrm{T}$ mycoplasmas were similarly examined, and the calculated DNA genome size was found to range from $4.1 \times 10^{8}$ to $4.8 \times$ $10^{8}$ daltons (8). These values were similar to those found in the sterol-requiring classical mycoplasmas.

Sensitivity to antibiotics. Growth of $T$ mycoplasmas in vitro is inhibited by the following antibiotics, listed in order of approximate decreasing effectiveness: the tetracyclines (including the semisynthetic tetracyclines), erythromycin, streptomycin, chloramphenicol, gentamycin, kanamycin, and partially by clindamycin $(9,20,66,74)$.

Resistance to antibiotics and antimicrobial agents. T mycoplasmas are resistant in vitro to the inhibitory properties of the following agents: the penicillins (including the semisynthetic penicillins), sulfadiazine and rifampin (Shepard and Lunceford, unpublished data), cephaloridine (controversial) $(9,17,74)$, aurothiomalate $(22,74)$, and lincomycin $(9,16$, 67). Lincomycin is especially useful in separation and purification of $\mathrm{T}$ mycoplasmas from $M$. hominis in specimens from the genitourinary tract, since $M$. hominis is selectively inhibited by this antibiotic (10). T mycoplasmas are essentially unaffected by the folic acid antagonist, trimethoprim lactate, at concentrations which are completely inhibitory to most strains of Proteus $(5 \mu \mathrm{g} / \mathrm{ml})$ in an agar system of pH 6.0 (Shepard and Lunceford, unpublished data).

Selective growth inhibition by antimicrobial agents. Growth of $\mathrm{T}$ mycoplasmas in vitro is selectively inhibited by the following agents: thallium acetate $(35,56,57,74)$, erythromycin $(10,66,74), 5$-iodo-2'-deoxyuridine (57), hydroxyurea (57), acetohydroxamic acid (Shepard and Lunceford, unpublished data), sorbyl-, benzoyl-, and 3-amino-benzoyl hydroxamic acids (22). Erythromycin selectively inhibits T-mycoplasma growth and is opposite in action to that of lincomycin, as described above (10). In contrast, the human classical mycoplasmas (except as noted below) are largely unaffected by these selective agents at concentrations which are completely inhibitory to $\mathrm{T}$ mycoplasmas. $M$. pneumoniae, however, like the T mycoplasmas, is sensitive to ery thromycin (58). Thallium acetate in concentrations stronger than 1:8000 $(0.0125 \%)$ have been noted to cause some inhibition even of classical mycoplasmas in agar cultures (19). The selective inhibition of $\mathrm{T}$ mycoplasmas in agar cultures by both erythromycin and thallium acetate is significantly enhanced at an alkaline $\mathrm{pH}$ of 7.5 (57).

Ether sensitivity. Human $\mathrm{T}$ mycoplasmas treated for $18 \mathrm{~h}$ at $4 \mathrm{C}$ in liquid medium containing $20 \%$ diethyl ether are killed by this treatment, as are three classical Mycoplasma species: $M$. hominis, $M$. pneumoniae, and $M$. bovigenitalium (74).

Effects of temperature: heat. The optimal temperature for growth and multiplication of $\mathrm{T}$ mycoplasmas in both fluid and agar cultures is 36 to $37 \mathrm{C}$. Higher temperatures adversely affect growth. Up to a fourfold reduction in growth may occur at $40 \mathrm{C}$, and no growth of eight T-mycoplasma serotypes occurs at $42 \mathrm{C}$ (6). Growth at $30 \mathrm{C}$ yielded colony numbers similar to those obtained at $37 \mathrm{C} \mathrm{(6)}$, and $30 \mathrm{C}$ incubation is ideal for continuous (24-hourly) subcultivation in broth (24). Slight reductions in titer are observed at $27 \mathrm{C}$; poorest growth is observed at $22 \mathrm{C}$ and $20 \mathrm{C}$ in agar cultures (6). Growth of T-mycoplasma serotypes III, V, VI, and VIII failed to occur in fluid cultures at 20 C (6). At the optimal temperature of 36 to 37 C, T-mycoplasma colonies generally remain viable for periods of 2 to 4 days, depending upon the strain and the medium employed.

$T$ mycoplasmas can be heat-inactivated at temperatures of $56 \mathrm{C}$ and $60 \mathrm{C}$. T-mycoplasma strains Reow and Johnson failed to survive $56 \mathrm{C}$ for $5 \mathrm{~min}$ (74). Heat inactivation of eight T-mycoplasma serotypes at a temperature of 60 C for $10 \mathrm{~min}$ was $100 \%$ only for serotypes $\mathrm{I}$, III, and IV. Treatment at the same temperature 
for 30 min resulted in complete inactivation of all eight serotypes (6). The thermal death time for $T$ mycoplasmas has not been precisely established, but it probably lies between 10 and $30 \mathrm{~min}$ at $60 \mathrm{C}$, and may be strain dependent.

Low temperature. T-mycoplasma broth cultures remain viable for periods up to 16 days at 4 C (20), and viable organisms may still be present after 3 to 4 months at $4 \mathrm{C}(6)$. T mycoplasmas in freshly inoculated broth of $\mathrm{pH}$ 6.0 will remain viable at room temperature (20 to $25 \mathrm{C}$ ) for periods up to 5 days or more, depending upon the strain (Shepard and Lunceford, unpublished data). The organisms in 16to 20-h fluid cultures of $\mathrm{pH} 6.0$ survive storage in the frozen state at temperatures of $-60 \mathrm{C}$ to $-85 \mathrm{C}$ for periods of a year or more (6; Shepard and Lunceford, unpublished data). Freeze-drying has proved to be a convenient method of preservation of $\mathrm{T}$ mycoplasmas, and such cultures (stored at $-20 \mathrm{C}$ to $-60 \mathrm{C}$ ) have been viable for at least 6 years (obtained from D. K. Ford).

Serology. The human $\mathrm{T}$ mycoplasmas are serologically distinct from all other recognized mycoplasmas and represent a serologically heterogeneous group. Six different serotypes were originally identified and shown to be antigenically distinct (21) on the basis of a metabolism-inhibition test $(48,49)$. Subsequently, the existence of seven T-mycoplasma serotypes was confirmed (3), and an eighth serotype was included later (4). The validity of these seven serotypes (plus serotype VIII) was established by comparative serology, employing four different serological methods: the metabolism-inhibition test, the growth-inhibition test, the indirect-immunofluorescence test, and the indirect-hemagglutination test (3). The growthinhibition test was recently further modified for application to the serological study of $T$ mycoplasmas. Several variables were examined, and a standardized procedure was established for $T$ mycoplasmas (4). In consideration of priority and the validation of serotypes by the above comparative studies, we recognize the serological classification proposed by $F$. T. Black, which establishes at least eight T-mycoplasma serotypes (types I through VIII) (3).

An immune-inactivation test for $T$ mycoplasmas has been developed which employs a complement-dependent, mycoplasmacidal reaction (36). Urea must be omitted from the reaction, since the ammonia produced by T-mycoplasma urease inactivates the $\mathrm{C} 4 \mathrm{com}$ ponent of the complement. Employing this complement-dependent, mycoplasmacidal test, the same authors demonstrated the presence of five serogroups on the basis of shared common antigens and of 11 serotypes within these five groups (38). Further, the serological heterogeneity of the human T-mycoplasma group was even more precisely defined, and each of the proposed 11 serotypes was further characterized by the presence of both major and minor antigens. It was further emphasized that T-mycoplasma primary isolates from the human genitourinary tract may consist of a mixture of more than one serotype (37). The specificity and sensitivity of the complement-dependent mycoplasmacidal test in comparison to the four different serological methods cited previously (3) for typing the T mycoplasmas are presently unknown. The precise relationship of the 11 T-mycoplasma serotypes found by the complement-dependent mycoplasmacidal test (38) to the earlier-established eight T-mycoplasma serotypes (3) must await comparative serological examination by different techniques.

Habitat. The human $T$ mycoplasmas occur chiefly in the male and female genitourinary tract and occasionally also in the pharynx and in the rectum $(21,49,58)$. The organisms were first isolated from male patients with nongonococcal urethritis (NGU), and they are associated with this disease $(53,54,59)$. T mycoplasmas can also be isolated from the genitourinary tract of apparently healthy adult individuals who are T-mycoplasma carriers or who harbor inapparent infections (59). The rate of association of $\mathrm{T}$ mycoplasmas in NGU patients, however, is more than twice the rate of association among adult male controls matched for age, average sexual activity, and occupation (service recruits) (59). The organisms have also been reported to colonize the genital tract and the pharynx of newborn infants $(25,33)$. Isolation rates of $\mathrm{T}$ mycoplasmas from controls and from NGU patients reported by other investigators, however, have varied widely (41). The organisms have been associated with reproductive failure in females $(14,26,28,34)$ and low birth-weight of newborn infants (11, 33) and have been isolated from cases of acute salpingitis (46). The possible pathogenic role of $T$ mycoplasmas in the human genitourinary tract is supported by the association of these organisms with puerperal sepsis (69) and amnionitis with mycoplasmemia (13) and by the recent finding of a direct, quantitative relationship between urine T-mycoplasma titers and return of symptoms of dysuria and urethritis in NGU patients after relapse to treatment with low regimens of tetracycline (60).

Although beyond the scope of the present communication, the existence of $\mathrm{T}$ myco- 
plasmas in animal species other than man should be emphasized and their importance in certain animal infections should be indicated. $T$ mycoplasmas have been isolated from the genital tracts of cattle $(73,74,76)$, the genital tracts of dogs (77), the throats of squirrel monkeys (77), the genital tracts of female talapoin, patas, and macaque monkeys (R. B. Kundsin, T. Rowell, and A. Parreno, Abstr. Annu. Meet. Amer. Soc. Microbiol. p. 80, 1973), and from the oropharynx of cats (71). A "San Angelo" strain of bovine T mycoplasma was isolated from pneumonic lung lesions of feedlot cattle during an epizootic of pneumonia. This strain appeared to be unrelated serologically to two human T-mycoplasma strains ( $\$ 960-16$ and $\# 2 \mathrm{~K} 160-9)$ and two bovine T-mycoplasma strains of urinary-tract origin (39). Pathogenic bovine T mycoplasmas, isolated from pneumonic calf lungs, produce pneumonia in experimentally inoculated calves (30), and these same pneumonic calf lung T-mycoplasma strains also produce clinical mastitis in cows by intramammary inoculation (29).

\section{TAXONOMIC CONSIDERATIONS}

The $\mathrm{T}$ mycoplasmas are distinguished by their production of urease and, therefore, by their ability to hydrolyze urea. This singular property significantly sets the $\mathrm{T}$ mycoplasmas apart from all other members of the Mycoplasmatales. In consideration of this distinguishing property, it is reasonable to propose establishing a new, separate genus in the family Mycoplasmataceae in which to classify the $\mathrm{T}$ mycoplasmas isolated from man and lower animals. The generic name Ureaplasma is proposed for these organisms. (U.re.a.plas'ma. M.L. fem. n. urea urea; Gr. neut. n. plasma something formed or a form; M.L. neut. n. Ureaplasma urea form, i.e., a form that requires or utilizes urea.) At present, a single human species is proposed containing at least eight serotypes (3): Ureaplasma urealyticum sp. nov. (u.re.a.ly'ti.cum. M.L. fem. n. urea urea; Gr. adj. lyticus dissolving or digesting; M.L. adj. urealyticus urea-dissolving or urea-digesting). The type strain is human strain 960-(CX8), serotype VIII (3), cloned eight times; it has been deposited in the American Type Culture Collection (ATCC), Rockville, Md., under the number 27618 . The type strain was originally isolated on 27 November 1961 in the laboratory of one of us (MCS). Strains of the first eight serotypes of Ureaplasma urealyticum have also been deposited in the American Type
Culture Collection, and they are listed with their respective ATCC accession numbers in Table 1.

The proposed establishment of a new genus, Ureaplasma, in the family Mycoplasmataceae provides a taxonomic framework within which presently known and future species of Ureaplasma may be classified. An advantage of forming a new genus is that it confers freedom to classify new species within the genus without the requirement of adhering to the principles formulated for the other genera. A numbered serotype of the human species Ureaplasma urealyticum is broadly equivalent to a named species within the genus Mycoplasma or Acholeplasma. We foresee the possible existence of a large number of antigenically distinct ureaplasmas within this serologically heterogeneous group. The virtue of the proposed system of classification based upon serotype numbering is that it provides for incorporation of new serotypes within the genus without the need for proposing a separate name for each of them. From the foregoing, it is our opinion that it would be inappropriate to name a further new human species of Ureaplasma solely on the basis that it was antigenically different from the existing known serotypes.

For the ureaplasmas isolated from animals other than man, it is suggested that proposals of further named species be based upon either the animal host of origin or upon special distin-

TABLE 1. History of the eight serotypes of Ureaplasma urealyticum

\begin{tabular}{l|lc|c}
\hline Serotype $^{a}$ & \multicolumn{2}{|c|}{$\begin{array}{c}\text { Source and } \\
\text { strain no. }\end{array}$} & ATCC no. \\
\hline I & Ford & 7 & 27813 \\
II & Ford & 23 & 27814 \\
III & Ford & 27 & 27815 \\
IV & Ford & 58 & 27816 \\
V & Ford & 354 & 27817 \\
VI & Ford & Pi & 27818 \\
VII & Ford & Co & 27819 \\
VIII & Shepard & $960-(C X 8)$ & 27618 \\
\hline
\end{tabular}

${ }^{a}$ Serotype designations are those proposed by F.T. Black (3).

${ }^{b}$ Ureaplasma urealyticum strains $7,23,27,354, \mathbf{P i}$, and $\mathrm{Co}$ were originally isolated by D. K. Ford who demonstrated that they were antigenically distinct (21). Ford subsequently isolated strain 58. These seven strains, together with type strain 960-(CX8) from M. C. Shepard, were subsequently studied by F. T. Black who proposed the above serological classification.

${ }^{c}$ ATCC, American Type Culture Collection, Rockville, Md. 20852. 
guishing biological characteristics, or both. In the light of present knowledge, it seems probable that a given named animal species of Ureaplasma will be serologically heterogeneous and contain several different serotypes in the manner of the human species, Ureaplasma urealyticum.

\section{SUMMARY OF THE DISTINGUISHING PROPERTIES OF UREAPLASMA \\ UREALYTICUM GEN. NOV., SP. NOV.}

Cellular morphology. Predominantly coccoidal to coccobacillary elements approximately $0.3 \mu \mathrm{m}$ in diameter, frequently growing in short filaments; they are bounded by a single trilaminar membrane. They are nonmotile, gram negative, and stain best with Giemsa or a similar stain.

Horse serum agar. Colonies generally are small (20 to $30 \mu \mathrm{m}$ in diameter) and are normally without zones of surface growth. Film and spots are absent. The borders of the colonies are irregular. Larger colonies are multilobate or "cauliflower head" in appearance. Under special conditions, surface growth zones may be produced which mimic classical Mycoplasma colonies.

Differential agar (Shepard and Lunceford [Bacteriol. Proc., p. 83, 1970]; revision in preparation). Manganese accretion colonies, which are dark, golden-brown in color by direct-transmitted light, are produced; they are white in color by oblique-reflected light or by oblique-transmitted light.

Horse serum broth. Generally clear without evidence of turbidity. Growth is rapid with maximum titers of $10^{6}$ to $10^{7} \mathrm{CCU} / \mathrm{ml}$ generally reached in 16 to $20 \mathrm{~h}$ of incubation at $36 \mathrm{C}$.

Preferred atmosphere. Five to fifteen percent carbon dioxide tension in air or nitrogen. There is good growth anaerobically at $\mathrm{pH} 6.0$ in the presence of carbon dioxide and poor growth aerobically (normal room atmosphere).

Optimal reaction for growth. $\mathrm{pH} 6.0 \pm 0.5$.

Action on carbohydrates. Carbohydrates are not fermented (as determined by acid production and conventional color-change methods).

Urea. Urea is hydrolyzed with the production of $\mathrm{CO}_{2}$ and ammonia.

Growth requirements. Urea (may not be an absolute requirement for all strains) and cholesterol are required for growth; they are usually provided by 10 to $20 \%$ horse serum enrichment.

Hemolysis. There is beta or alpha-prime hemolysis of guinea pig erythrocytes by the blood-agar overlay method and variable hemolysis of human and sheep erythrocytes. Beta hemolysis of guinea pig and rabbit erythrocytes occurs when tested by a simplified blood-agar, poured-plate method. There is beta hemolysis of guinea pig erythrocytes in fluid medium.

Cell adsorption. Agar colonies adsorb $\mathrm{HeLa}$ cells from cell suspensions.

Enzymatic activities. Urease and phosphatase are produced. Carbohydrates are not fermented, as determined by acid production. Hexokinase, arginine deiminase, and catalase are not produced. Tetrazolium and methylene blue are not reduced.

Selective growth inhibition by inhibitors. Thallium acetate, ery thromycin, 5-iodo-2'-deoxyuridine, hydroxyurea, and hydroxamic acids are inhibitory to growth.

Antigenicity. Serological heterogeneity is demonstrated by metabolism-inhibition and immune-inhibition tests. There are at least eight different serotypes. Cell protein electrophoretic patterns of the different strains resemble each other closely, suggesting a single common group or species.

Habitat. Human genitourinary tract; occasionally also found in the pharynx and in the rectum.

Pathogenicity. The pathogenicity of this organism is controversial. In males, it is associated with nongonococcal urethritis and prostatitis; in females, with genitourinary tract infections and reproductive failure.

Type strain. Human strain 960-(CX8), serotype VIII (= ATCC no. 27618).

\section{ACKNOWLEDGMENTS}

We are deeply indebted to Ruth G. Wittler and to Erwin F. Lessel for their generous taxonomic assistance and to D. G. ff. Edward, E. A. Freundt, and Leonard Hayflick for their helpful suggestions and comments.

\section{ADDENDUM IN PROOF}

The importance of type and concentration of agar and of magnesium and substances in Ionagar on growth and colony morphology of $\mathrm{T}$ mycoplasmas was recently emphasized by $G$. Furness (J. Infect. Dis. 128:703-709, 1973). His findings suggested further that $\mathrm{T}$ mycoplasmas have different requirements for growth, and strain-to-strain differences are evident.

\section{REPRINT REQUESTS}

Address reprint requests to: Dr. M. C. Shepard, Division of Microbiology, Naval Medical Field Research Laboratory, Camp Lejeune, N.C. 28542. 


\section{LITERATURE CITED}

1. Bak, L. A., and F. T. Black. 1968. DNA base composition of human $\mathrm{T}$ strain mycoplasmas. Nature (London) 219:1044-1045.

2. Bak, L. A., F. T. Black, C. Christiansen, and E. A. Freundt. 1969. Genome size of mycoplasmal DNA. Nature (London) 224:1 209-1210.

3. Black, F. T. 1970. Serological methods for classification of human T mycoplasmas. Fifth Int. Congr. Infect. Dis., Vienna, Austria 1:407411.

4. Black, F. T. 1973. Modifications of the growth inhibition test and its application to human T-mycoplasmas. Appl. Microbiol. 25:528-533.

5. Black, F. T. 1973. Phosphatase activity in T-mycoplasmas. Int. J. Syst. Bacteriol. 23:65-66.

6. Black, F. T. 1973. Biological and physical properties of human T-mycoplasmas. Ann. N. Y. Acad. Sci. 225:131-143.

7. Black, F. T., A. Birch-Andersen, and E. A. Freundt. 1972 Morphology and ultrastructure of human $\mathrm{T}$ mycoplasmas. J. Bacteriol. 111:254259.

8. Black, F. T., C. Christiansen, and G. Askaa. 1972. Genome size and base composition of deoxyribonucleic acid from eight human T-mycoplasmas. Int. J. Syst. Bacteriol. 22:241-242.

9. Braun, P., J. O. Klein, and E. H. Kass. 1970. Susceptibility of genital mycoplasmas to antimicrobial agents. Appl. Microbiol. 19:62-70.

10. Braun, P., J. O. Klein, Y.-H. Lee, and E. H. Kass. 1970. Methodologic investigations and prevalence of genital mycoplasmas in pregnancy. J. Infect. Dis. 121:391 400 .

11. Braun, P., Y-H. Lee, J. O. Klein, S. M. Marcy, T. A. Klein, D. Charles, P. Levy, and E. H. Kass. 1971. Birth weight and genital mycoplasmas in pregnancy. N. Engl. J. Med. 284:167-171.

12. Brighton, W. D., G. D. Windsor, B. E. Andrews, and R. E. O. Williams. 1967. Continuous culture of mycoplasma species. Monthly Bulletin of the Ministry of Health and the Public Health Laboratory Service (London) 26:154-158.

13. Caspi, E., E. Herczeg, F. Solomon, and D. Sompolinsky. 1971. Amnionitis and T-strain mycoplasmemia. Am. J. Obstet. Gynecol. 111: 1102-1106.

14. Caspi, E., F. Solomon, and D. Sompolinski. 1972. Early abortion and mycoplasma infection. Israel J. Med. Sci. 8:122-127.

15. Clyde, W. A., Jr. 1963. Hemolysis in identifying Eaton's pleuropneumonia-like organism. Science 139:55.

16. Csonka, G. W., and J. Corse. 1970. Selective inhibition in vitro of Mycoplasma hominis by lincomycin. Brit. J. Vener. Dis. 46:203-204.

17. Csonka, G. W., R. E. O. Williams, and J. Corse. 1967. $T$ strain mycoplasma in nongonococcal urethritis. Ann. N. Y. Acad. Sci. 143:794-798.

18. Dienes, L., M. W. Ropes, W. E. Smith, S. Madoff, and W. Bauer. 1948. The role of pleuropneumonia-like organisms in genitourinary and joint diseases. N. Engl. J. Med. 238:509-515/563-567.

19. Edward, D. G. ff. 1947. A selective medium for pleuropneumonia-like organisms. J. Gen. Microbiol. 1:238-243.
20. Ford, D. K. 1962. Culture of human genital "T-strain" pleuropneumonia-like organisms. J. Bacteriol. 84:1028-1034.

21. Ford, D. K. 1967. Relationships between mycoplasma and the etiology of nongonococcal urethritis and Reiter's syndrome. Ann. N. Y. Acad. Sci. 143:501-504.

22. Ford, D. K. 1972. Inhibition of growth of T-strain mycoplasmas by hydroxamic acids and by aurothiomalate. Antimicrob. Ag. Chemother. 2: 340-343.

23. Ford, D. K., K. L. McCandlish, and A. F. Gronlund. 1970. Metabolism of ${ }^{14} \mathrm{C}$-urea by T-strain mycoplasma. J. Bacteriol. 102:605-606.

24. Ford, D. K., and J. MacDonald. 1967. Influence of urea on the growth of T-strain mycoplasmas. J. Bacteriol. 93:1509-1512.

25. Foy, H. M., G. E. Kenny, E. M. Levinsohn, and J. T. Grayston. 1970. Acquisition of mycoplasmata and $\mathrm{T}$-strains during infancy. J. Infect. Dis. 121:579-587.

26. Friberg, J., and H. Gnarpe. 1973. Pregnancies in "infertile" couples treated with doxycycline for T-mycoplasmas. Amer. J. Obstet. Gynecol. 116: 23-26.

27. Furness, G. 1973. T-mycoplasmas: their growth and production of a toxic substance in broth. $\mathrm{J}$. Infect. Dis. 127:9-16.

28. Gnarpe, H., and J. Friberg. 1972. Mycoplasma and human reproductive failure. I. The occurrence of different Mycoplasmas in couples with reproductive failure. Amer. J. Obstet. Gynecol. 114: 727-731.

29. Gourlay, R. N., C. J. Howard, and J. Brownlie. 1972. The production of mastitis in cows by the intramammary inoculation of $\mathrm{T}$-mycoplasmas. $\mathrm{J}$. Hyg. 70:511-521.

30. Gourlay, R. N., and L. H. Thomas. 1970. The experimental production of pneumonia in calves by the endobronchial inoculation of T-mycoplasmas. J. Comp. Pathol. 80:585-594.

31. Grant, C. L., and D. Pramer. 1962. Minor element composition of yeast extract. J. Bacteriol. 84: 869-870.

32. Hendley, J. O., and E. N. Allred. 1972. Prolonged stationary-phase growth of $\mathrm{T}$-strain mycoplasmas in broth culture. Infect. Immunity 5:164-168.

33. Klein, J. O., D. Buckland, and M. Finland. 1969. Colonization of newborn infants by mycoplasmas. N. Engl. J. Med. 280:1025-1030.

34. Kundsin, R. B., S. G. Driscoll, and P. L. Ming. 1967. A strain of mycoplasma associated with human reproductive failure. Science 157:15731574.

35. Lee, Y-H., P. E. Bailey, and W. M. McCormack. 1972. T mycoplasmas from urine and vaginal specimens: decreased rates of isolation and growth in the presence of thallium acetate. $J$. Infect. Dis. 125:318-321.

36. Lin, J-S., and E. H. Kass. 1970. Immune inactivation of T-strain mycoplasmas. J. Infect. Dis. 122:93-95.

37. Lin, J-S., and E. H. Kass. 1973. Serotypic heterogeneity in isolates of human genital Tmy coplasmas. Infect. Immunity 7:499-500.

38. Lin, J-S. L., M. I. Kendrick, and E. H. Kass. 1972. 
Serological typing of human genital T-mycoplasmas by a complement-dependent mycoplasmacidal test. J. Infect. Dis. 126:658-663.

39. Livingston, C. W., Jr. 1972. Isolation of T-strain of mycoplasma from Texas feedlot cattle. Amer. J. Vet. Res. 33:1925-1929.

40. Low, I. E., M. D. Eaton, and P. Proctor. 1968. Relation of catalase to substrate utilization by Mycoplasma pneumoniae. J. Bacteriol. 95:14251430 .

41. McCormack, W. M., P. Braun, Y-H. Lee, J. O. Klein, and E. H. Kass. 1973. The genital mycoplasmas. N. Engl. J. Med. 288:78-89.

42. McGee, A. Z., M. Rogul, and R. G. Wittler. 1967. Molecular genetic studies of relationships among mycoplasma, L-forms and bacteria. Ann. N. Y. Acad. Sci. 143:21-30.

43. Madoff, S. 1960. Isolation and identification of PPLO. Ann. N. Y. Acad. Sci. 79:383-392.

44. Manchee, R. J., and D. Taylor-Robinson. 1969. Enhanced growth of T-strain mycoplasmas with $N$-2-hydroxyethyl piperazine- $N^{\prime}$-2-ethanesulfonic acid buffer. J. Bacteriol. 100:78-85.

45. Manchee, R. J., and D. Taylor-Robinson. 1970. Lysis and protection of erythrocytes by T-mycoplasmas. J. Med. Microbiol. 3:539-546.

46. Mårdh, P-A., and L. Westrom. 1970. T-mycoplasmas in the genitourinary tract of the female. Acta Pathol. Microbiol. Scand. 78:367-374.

47. Masover, G. K., and L. Hayflick. 1973. Growth of T-strain mycoplasmas in media without added urea. Ann. N. Y. Acad. Sci. 225:118-130.

48. Purcell, R. H., D. Taylor-Robinson, D. Wong, and R. M. Chanock. 1966. Color test for the measurement of antibody to T-strain mycoplasmas. J. Bacteriol. 92:6-12.

49. Purcell, R. H., D. Wong, R. M. Chanock, D. Taylor-Robinson, J. Canchola, and J. Valdesuso. 1967. Significance of antibody to mycoplasma as measured by metabolic-inhibition techniques. Ann. N. Y. Acad. Sci. 143:664-675.

50. Razin, S., J. Valdesuso, R. H. Purcell, and R. M. Chanock. 1970. Electrophoretic analysis of cell proteins of $\mathrm{T}$-strain mycoplasmas isolated from man. J. Bacteriol. 103:702-706.

51. Romano, N., P. F. Smith, and W. R. Mayberry. 1972. The lipids of a T-strain of mycoplasma. J. Bacteriol. 109:565-569.

52. Rottem, S., E. A. Pfendt, and L. Hayflick. 1971. Sterol requirements of T-strain mycoplasmas. J. Bacteriol. 105:323-330.

53. Shepard, M. C. 1954 . The recovery of pleuropneumonia-like organisms from Negro men with and without nongonococcal urethritis. Amer. J. Syph. Gonor. Vener. Dis. 38:113-124.

54. Shepard, M. C. 1956. T-form colonies of pleuropneumonialike organisms. J. Bacteriol. 71:362369.

55. Shepard, M. C. 1957. Visualization and morphology of pleuropneumonialike organisms in clinical material. J. Bacteriol. 73:162-171.

56. Shepard, M. C. 1966 . Human mycoplasma infections. Health Lab. Sci. 3:163-169.

57. Shepard, M. C. 1967. Cultivation and properties of T-strains of mycoplasma associated with nongonococcal urethritis. Ann. N. Y. Acad. Sci.
143:505-514.

58. Shepard, M. C. 1969. Fundamental biology of the T-strains. In L. Hayflick (ed.), The mycoplasmatales and the L-phase of bacteria. AppletonCentury-Crofts, New York.

59. Shepard, M. C. 1970. Nongonococcal urethritis associated with human strains of "T" mycoplasmas. J. Amer. Med. Ass. 211:1335-1340.

60. Shepard, M. C. 1973. T-strain mycoplasmas as a cause of urethritis. Epidemic venereal disease. Proc. Second Int. Vener. Dis. Symp., St. Louis, Missouri, 1972, p. 83-87.

61. Shepard, M. C. 1973. Differential methods for identification of T-mycoplasmas based on demonstration of urease. J. Infect. Dis. 127(suppl):S22S25.

62. Shepard, M. C., and D. R. Howard. 1970. Identification of " $\mathrm{T}$ " mycoplasmas in primary agar cultures by means of a direct test for urease. Ann. N. Y. Acad. Sci. 174:809-819.

63. Shepard, M. C., and C. D. Lunceford. 1965. Effect of $\mathrm{pH}$ on human mycoplasma strains. J. Bacteriol. 89:265-270.

64. Shepard, M. C., and C. D. Lunceford. 1967. Occurrence of urease in T-strains of mycoplasma. J. Bacteriol. 93:1513-1520.

65. Shepard, M. C., and C. D. Lunceford. 1970. Urease color test medium U-9 for the detection and identification of " $T$ " mycoplasmas in clinical material. Appl. Microbiol. 20:539-543.

66. Shepard, M. C., C. D. Lunceford, and R. L. Baker. 1966. T-strain mycoplasma. Selective inhibition by erythromycin in vitro. Brit. J. Vener. Dis. 42:21-24.

67. Shipley, A. S., J. Bowman, and J. J. O'Connor. 1968. T-strain mycoplasmas in non-specific urethritis. Med. J. Aust. 1:794-796.

68. Somerson, N., D. Taylor-Robinson, and R. M. Chanock. 1963. Hemolysin production as an aid in the identification and quantitation of Eaton agent (Mycoplasma pneumoniae). Amer. J. Hyg. 77:122-128.

69. Sompolinsky, D., F. Solomon, H. Leiba, E. Caspi, G. Lewinsohn, and C. Almog. 1971. Puerperal sepsis due to T-strain mycoplasma. Israel J. Med. Sci. 7:745-748.

70. Sueltmann, S., V. Allen, S. L. Inhorn, and J. M. Benforado. 1971. Study of mycoplasma in university students with non-gonococcal urethritis. Health Lab. Sci. 8:62-66.

71. Tan, R. J. S., and J. G. Markham. 1971. Feline T-strain mycoplasmas. Jap. J. Exp. Med. 41:247248.

72. Taylor-Robinson, D., and R. H. Purcell. 1966. Mycoplasmas of the human urogenital tract and oropharynx and their possible role in disease: a review with some recent observations. Proc. Roy. Soc. Med. 59:1112-1116.

73. Taylor-Robinson, D., D. A. Haig, and M. H. Williams. 1967. Bovine T-strain mycoplasma. Ann. N. Y. Acad. Sci. 143:517-518.

74. Taylor-Robinson, D., M. H. Williams, and D. A. Haig. 1968. The isolation and comparative biological and physical characteristics of T-mycoplasmas of cattle. J. Gen. Microbiol. 54:33-46.

75. Taylor-Robinson, D., J. P. Addey, and C. S. 
Goodwin. 1969. Comparison of techniques for the isolation of $\mathrm{T}$-strain mycoplasmas. Nature (London) 222:274-275.

76. Taylor-Robinson, D., M. Thomas, and P. L. Dawson. 1969. The isolation of T-mycoplasmas from the urogenital tract of bulls. J. Med. Microbiol. 2:527-533.

77. Taylor-Robinson, D., C. Martin-Bourgon, T. Watanabe, and J. P. Addey. 1971. Isolation of T-mycoplasmas from dogs and squirrel monkeys: biological and serological comparison with those isolated from man and cattle. J. Gen. Microbiol. 68:97-107.

78. Weibull, C., and K. Hammarberg. 1962. Occurrence of catalase in pleuropneumonia-like organisms and bacterial L-forms. J. Bacteriol. 84:520-525.

79. Woodson, B. A., K. S. McCarty, and M. C. Shepard. 1965. Arginine metabolism in mycoplasma and infected strain L-929 fibroblasts. Arch. Biochem. 109:364-371. 